\title{
Combined Antero-Posterior Inverted-U Metaphyseal and Open-Wedge Medial-Epiphyseal Osteotomy for Advanced Blount Disease
}

\author{
Alfred O. Ogbemudia ${ }^{*}$, Anirejuoritse Bafor'1, Ehimwenma J. Ogbemudia², \\ Edwin Edomwonyi ${ }^{3}$ \\ ${ }^{1}$ Department of Orthopaedics and Trauma, University of Benin Teaching Hospital, Benin City, Nigeria \\ ${ }^{2}$ Department of Medicine, University of Benin, Benin City, Nigeria \\ ${ }^{3}$ Department of Orthopaedics and Trauma, Irrua Specialist Teaching Hospital, Irrua, Nigeria \\ Email: ${ }^{*}$ alfredoghogho@yahoo.com
}

Received 16 February 2015; accepted 3 April 2015; published 9 April 2015

Copyright (C) 2015 by authors and Scientific Research Publishing Inc.

This work is licensed under the Creative Commons Attribution International License (CC BY). http://creativecommons.org/licenses/by/4.0/

(c) (i) Open Access

\begin{abstract}
Background: Blount disease is frequently associated with deformities that may not be adequately corrected by a single metaphyseal osteotomy. This study evaluated the outcome of a combined metaphyseal and epiphyseal osteotomy in severe cases. Methods: We prospectively evaluated the outcome of combining the antero-posterior inverted-U metaphyseal osteotomy with a medial open-wedge hemi-epiphyseal osteotomy in eighteen patients (27 tibiae) with Stage IV to VI Blount disease. Results: The average age of patients was 9 years (ranging from 5 to 17). The tibio-femoral angle improved from $43^{\circ}$ varus (Range: $34^{\circ}-78^{\circ}$ ) to $2^{\circ}$ varus (Range: $5^{\circ}$ valgus to $8^{\circ}$ varus). The metaphyseal-diaphyseal angle improved from $36^{\circ}$ to $8^{\circ}$ varus. Internal tibial torsion improved from $39^{\circ}$ to $2^{\circ}$. All the patients were able to achieve $110^{\circ}$ of knee flexion in a year. Conclusion: In conclusion, the combined metaphyseal and epiphyseal osteotomy satisfactorily corrected tibiofemoral and metaphyseal-diaphyseal varus and internal tibial torsion without recurrence in patients with severe Blount disease. Level of Evidence: IV.
\end{abstract}

\section{Keywords}

Blount Disease, Double Osteotomy, Tibial Osteotomy, Blount Disease

\footnotetext{
${ }^{*}$ Corresponding author.
}

How to cite this paper: Ogbemudia, A.O., Bafor, A., Ogbemudia, E.J. and Edomwonyi, E. (2015) Combined Antero-Posterior Inverted-U Metaphyseal and Open-Wedge Medial-Epiphyseal Osteotomy for Advanced Blount Disease. Surgical Science, 6, 162-169. http://dx.doi.org/10.4236/ss.2015.64026 


\section{Introduction}

Severe Blount disease is a complex of deformities which include: internal torsion and procurvatum of the tibia; shortening of the leg, genu varum, distal femoral torsion [1], medial condyle overgrowth and depression of the medial tibial plateau. It is known to be common amongst blacks [2] [3]. With improvement in nutritional supplements and the abundant sunlight in sub-Saharan Africa, Blount disease should become a leading cause of genu varum in black Africa when compared with nutritional rickets. Orthopaedic surgeons in heavily populated black nations will likely see many more patients with Blount disease. The myriad of deformities in severe Blount disease makes operative correction of the disease a classic challenge. The goals of operative treatment include the restoration of the mechanical axis of the limb at the knee to about $5^{\circ}$ of valgus, correction of limb length discrepancy, varus deformity and internal tibial torsion [2]. The extent of operative treatment is dependent on the severity of the associated deformities. The classification by Langenskiold [2]-[4] is used to stage the disease. Osteotomy at the metaphysis is expected to correct varus deformity and torsion of the tibial but not severe depression of the medial tibial plateau which would require medial hemi-epiphyseal osteotomy. Lateral hemi-epiphyseodesis of the proximal tibia is only consistent in correcting genu varum and not the depression of the medial tibial plateau. In addition to the inadequacy of a single metaphyseal or epiphyseal osteotomy or lateral tibial hemi-epiphyseodesis in addressing most of the deformities in Blount disease, there is also the issue of stability at the osteotomy site following concomitant osteotomy of the fibula. Various forms of osteotomy have been described in the literature [5]-[10] with variable capacity to address the deformities associated with Blount disease. The stability of the skeletal framework of the limb is compromised by osteotomy of both fibula and tibia within the proximal third of the leg which necessitates the use of external fixators, Kirschner wires or Blount staples. To meet the goals of operative treatment and address the instability associated with osteotomy of the tibia and fibula at the same level, fibular osteotomy at the junction between its middle and distal third, proximal tibial metaphyseal osteotomy in the shape of an inverted-U in the antero-posterior plane were done alongside a medial hemicondylar open-wedge osteotomy of the epiphysis and reefing of the lateral collateral ligament. The procedures were done without image intensifier guide and the outcome and complications form the focus of this article.

\section{Patients and Method}

All patients presenting with Blount disease of Langenskiold stage IV and above were candidates for inclusion. We excluded any patient with: 1) a history of sickle cell anaemia; 2) rickets and 3) recurrent Blount disease. The patients were recruited from the orthopaedic clinics of two centres in the same city and operated by the first author from May 2005 to April 2011. Institutional research and ethics committee approval was obtained. Informed consent for surgery was obtained from each parent or guardian. The demographic, clinical and radiologic features of the patients were noted including the tibiofemoral angle and metaphyseal-diaphyseal angle. Associated extent of internal tibial torsion was assessed based on the deviation of the foot from the normal axis of the toes which was taken to be " 11 o'clock" for the right foot and " 1 o'clock" for the left foot on an imaginary clock centred at the heel of a supine patient. The metaphyseal-diaphyseal angle and tibiofemoral angles were measured using standing antero-posterior radiographs of the knees (Figure 1). Clinical photographs of patients were also obtained prior to and after removal of casts (Figure 2 and Figure 3).

All study patients had the combined metaphyseal antero-posterior inverted-U and open-wedge medial hemiepiphyseal osteotomy of the proximal tibia.

Just before the application of sterile drapes, we re-assessed the posterior tibial and dorsalis pedis arterial pulsations. The states of the sensory and motor innervation to the skin and muscles below the knee were assessed and documented on the ward within 24 hours before surgery.

Operative technique:

The operative technique comprised of the following components in order of precedence: 1) Fibula osteotomy with resection of about $1 \mathrm{~cm}$ of it at about $15 \mathrm{~cm}$ above the ankle joint; 2) Reefing of lax lateral collateral ligament of the knee; 3) A medially-based intra-epiphyseal open-wedge osteotomy; 4) An inverted-U anteroposterior proximal tibial metaphyseal osteotomy; 5) Fasciotomy of the anterior compartment by subcutaneous extension of the fascial incision.

All patients had pre-operative planning with determination of the level and orientation of osteotomy using a plain radiograph and translucent tracing paper. The tracing paper which had markings of the line, level and 


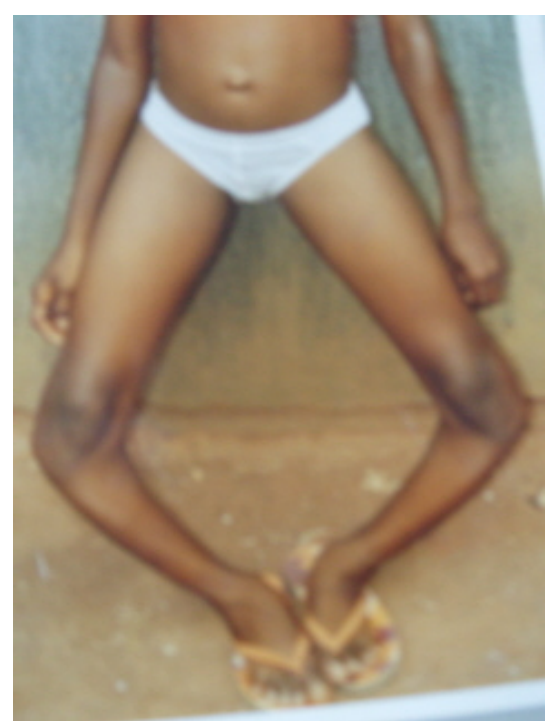

Figure 1. The clinical photograph of the index patient (pre-operation).

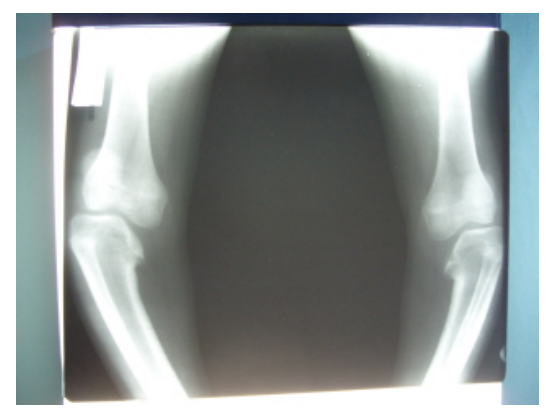

Figure 2. Pre-operative X-ray (AP view) of both knees (index patient in the series).

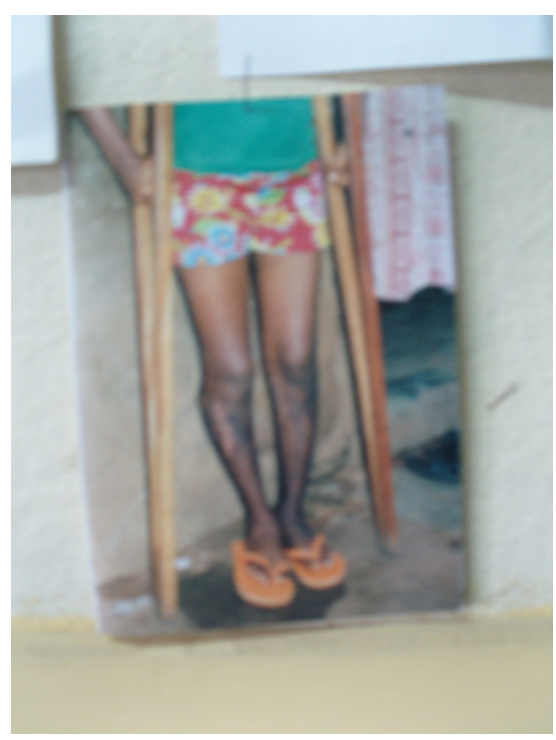

Figure 3. The clinical photograph of the patient in Figure 1 and Figure 2 (postoperation). 
height of osteotomy was placed on a viewing box intra-operatively.

Prophylactic ceftriazone $25 \mathrm{mg}$ per $\mathrm{kg}$ and metronidazole $7.5 \mathrm{mg}$ per $\mathrm{kg}$ body weight were given intravenously. Under tourniquet with a maximum tourniquet time of 150 minutes [11], the fibular and proximal tibial metaphyseal antero-posterior inverted-U osteotomies were done [12]. The open wedge hemi-condylar osteotomy of the medial plateau without fluoroscopic guide was made possible and relatively safe by a medial and a lateral incision which allowed direct visualization of the medial epiphyseal "beak" and access to the posterior periosteum for adequate protection of neurovascular structures. The insertion of the pes anserinus was reflected off the medial condyle by sharp dissection with the knee maintained at 45 degrees of flexion. Perforations were made about 4 to $5 \mathrm{~mm}$ apart with a $2.5 \mathrm{~mm}$ or $2.7 \mathrm{~mm}$ drill bit with the bit "roughly" directed at the lateral (Femoral) condyle. The drill points were connected with a $5 \mathrm{~mm}$ osteotome and then the osteotomy was completed with a $2.5 \mathrm{~cm}$ wide osteotome which also served to open a wedge into which $1 \mathrm{~cm}$ of resected fibula was insinuated (Figure 4 and Figure 5). The aid of an intra-operative fluoroscopy will eliminate the risk of injury to the growth plate. The relationship of the head of the fibula and the medial epiphyseal "beak" to the tibial growth plate on the radiograph were used as a rough guide to the level and orientation of the intra-epiphyseal osteotomy. To maintain the elevation of the medial plateau, the pes anserinus was attached to perforations in the elevated medial condyle. This is believed to offer an active restraint to loss of elevation. Furthermore, a proximally-based flap of deep fascia from the medial incision was placed underneath the elevated medial wedge before insinuating the resected piece of fibula to further maintain medial plateau elevation. It is believed that the flap of fascia be-

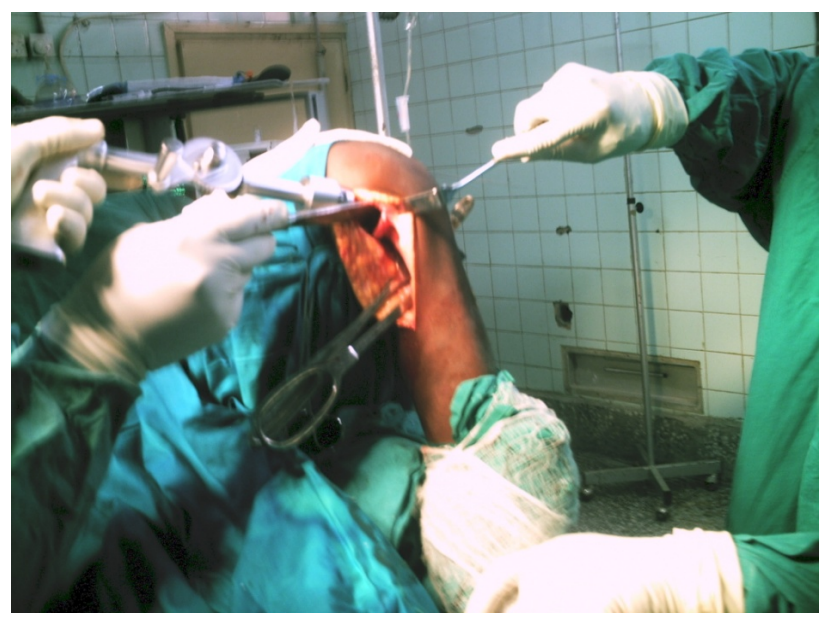

Figure 4. Intra-operative view of the medial hemi-epiphyseal open-wedge osteotomy.

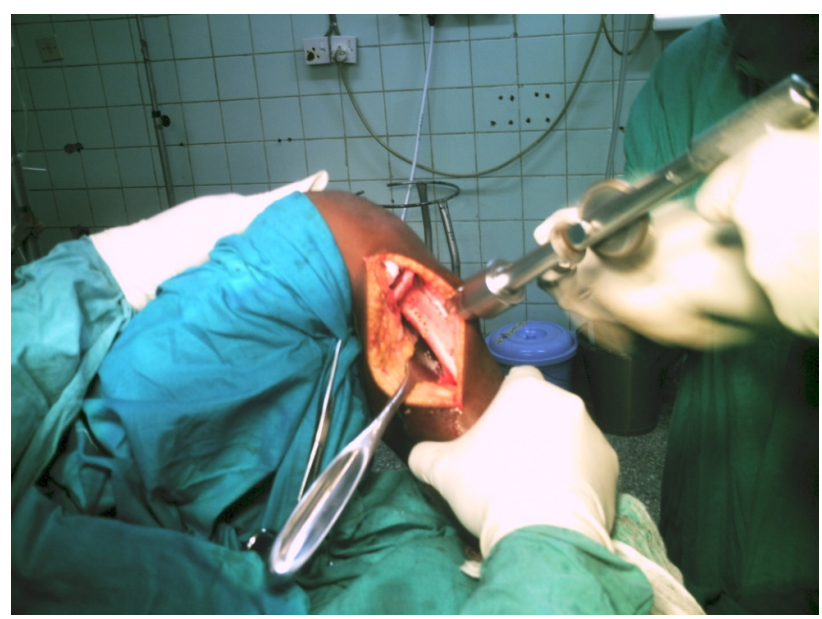

Figure 5. Intra-operative view of the use of a drill to define the orientation of the inverted-U metaphyseal osteotomy line. 
tween the cortical fibula and the cancellous/cartilaginous medial hemi-epiphyseal open wedge osteotomy will encourage non-union between the insinuated fibula and its host. This fibrous non-union is desirable in order to minimize recurrence of the medial physeal arrest. The wounds were closed in layers with a vacuum drain placed medially. The internal rotation deformity was completely corrected and the varus deformity was corrected fully or short of the point where the pulsatility of the dorsalis pedis artery became less palpable.

Post-operatively, each operated limb was elevated on a pillow for first five days after surgery with the aim of further preventing compartment syndrome or reducing its severity. Wound drain was discontinued on the second day post-operation. Ceftriazone $25 \mathrm{mg}$ per kg was given daily for five days. On the 14th day post-operation, the POP back-slab and skin sutures were removed. Manipulation and application of above knee scotch cast-brace with a hinge each on the medial and lateral side of the knee to enable commencement of active and passive flexion was done on the fourteenth day post-operation (Figure 6 and Figure 7). Complications like vascular insufficiency, peroneal nerve palsy, infection, residual deformity/ligament laxity, and recurrence of deformity as well as the presence of pain at rest or during weight bearing, limitation of flexion or swelling at the knee were sought for in the post-operative period. Patients were discharged with axillary crutches for partial weight bearing ambulation in the third week post-operation. The cast-brace was removed at sixteen weeks and partial weight bearing with bilateral axillary crutches continued for another eight weeks followed by ambulation under protection with a removable hinged knee brace for twenty-four weeks before commencement of unprotected weight bearing. Clinical outcome was measured using the following criteria: 1) degree of satisfactory re-alignment of the tibiofemoral angle; 2) the degree of correction of the metaphyseo-diaphyseal angle; 3) the extent of correction of internal torsion of the tibia; 4) attainment of 100 degrees of knee flexion; 5) absence of residual lateral collateral ligament laxity at the completion of one year post-operation. Satisfactory status on all five scores is deemed as excellent, on four is deemed as good while satisfaction on two or three of the preceding criteria is fair. A score of one or zero is considered a poor outcome.

During follow-up, radiologic assessment of callus formation was done at six, sixteen and twenty-eight weeks.

The satisfaction of the patients and their parents or guardians was also assessed one year after surgery.

\section{Results}

There were eighteen patients who had the combined metaphyseal antero-posterior inverted-U and open-wedge medial hemi-epiphyseal osteotomy of the proximal tibia. Eleven females (17 limbs) and seven males (ten limbs) made up the group-(Male:Female ratio $=1: 1.57$ ). In six females and three males both limbs were affected. The average tibio-femoral angle was $43^{\circ}$ (Range: $34^{\circ}-78^{\circ}$ ). The mean age of the patients at the time of surgery was 9 (nine) years (Range: 5 - 17 years). Clinical and demographic features of the patients are shown in Table 1.

Complications following the procedure are detailed in (Table 2).

Sixteen patients had good outcome while two had fair outcome based on the criteria enumerated in the methodology. All the patients were able to achieve $110^{\circ}$ of knee flexion at 52 weeks.

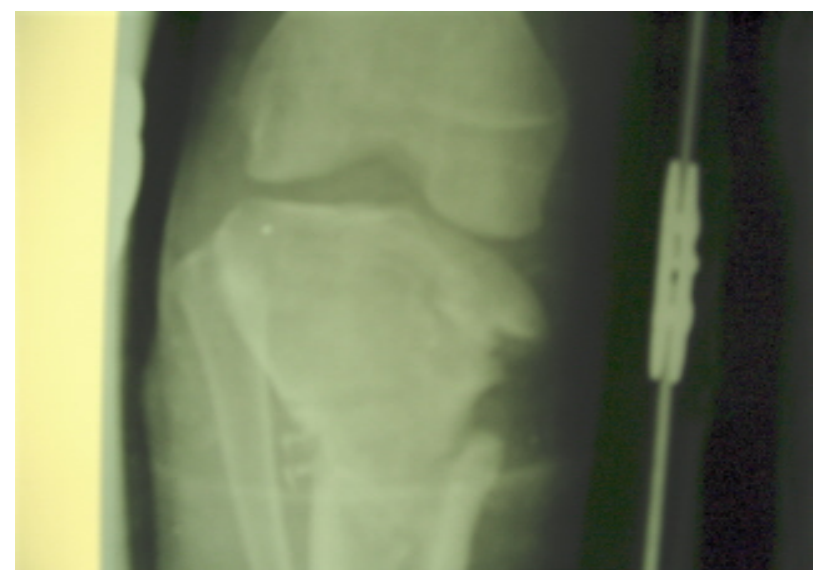

Figure 6. Anteroposterior radiograph after a medial epiphyseal open-wedge osteotomy and inverted-U metaphyseal osteotomy showing the metallic hinge of a cast-brace. 


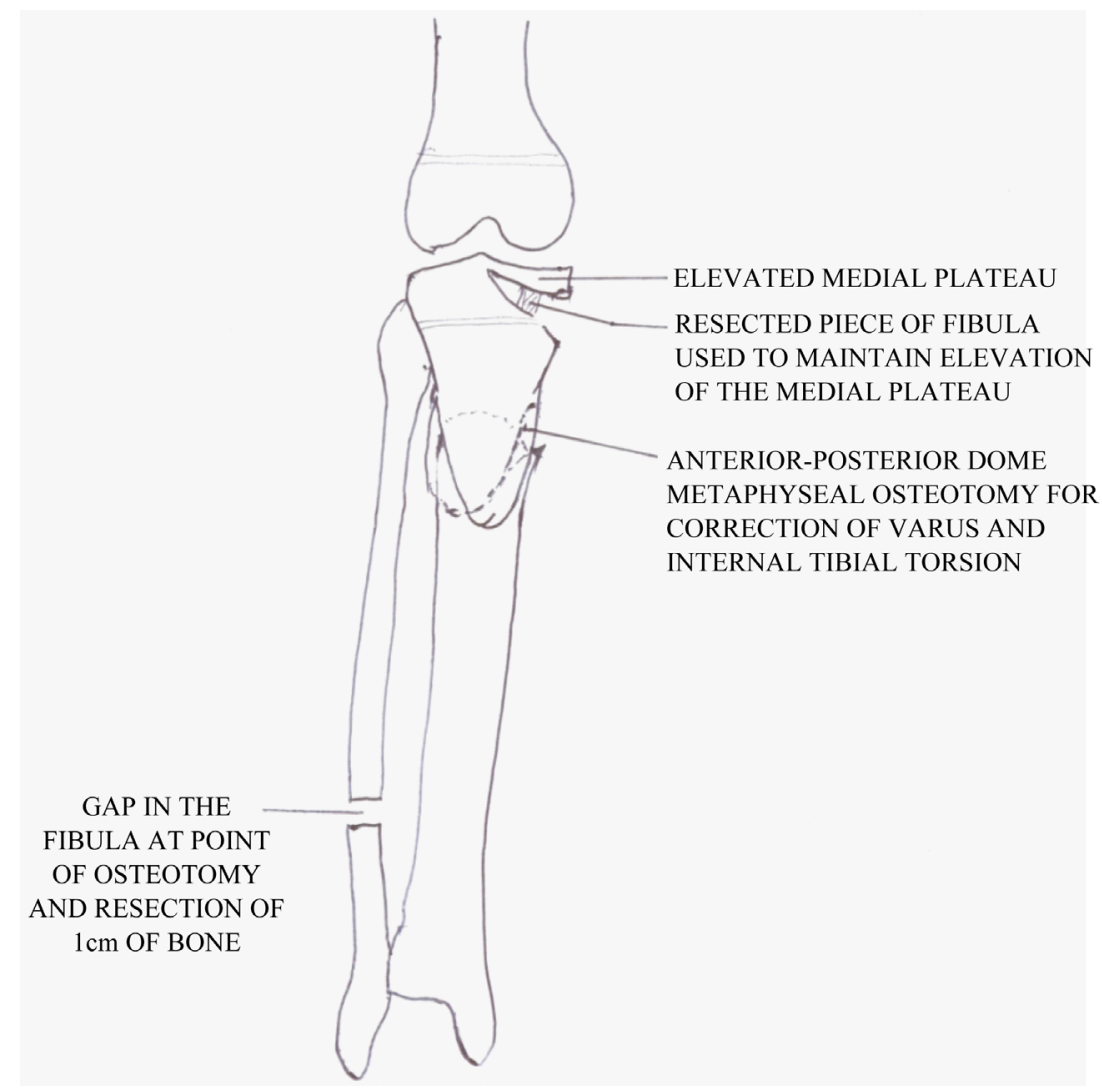

Figure 7. Line diagram of a right tibia at completion of fibular, proximal tibia metaphyseal and hemi-epiphyseal osteotomies in severe Blount disease.

Table 1. Clinical and demographic features of the study group.

\begin{tabular}{cc} 
Features & Values \\
\hline Age & $9(5-17)$ years. \\
Tibio-femoral angle (pre-operation) & $43^{\circ}\left(34^{\circ}-78^{\circ}\right)$ \\
Tibio-femoral angle (post-operation) & $-2^{\circ}\left(-5^{\circ}\right.$ to $\left.8^{\circ}\right)$ \\
Metaphyseal-diaphyseal angle (pre-operation) & $36^{\circ}\left(25^{\circ}\right.$ to $\left.54^{\circ}\right)$ \\
Metaphyseal-diaphyseal angle (post-operation) & $8^{\circ}\left(3^{\circ}\right.$ to $\left.14^{\circ}\right)$ \\
Varus (clinical goniometry) - pre-operation & $39^{\circ}\left(23^{\circ}-60^{\circ}\right)$ \\
Varus (clinical goniometry) - post-operation & $5^{\circ}\left(-3^{\circ}\right.$ to $\left.10^{\circ}\right)$ \\
Internal tibial torsion (pre-operation) & $-39^{\circ}\left(-65^{\circ}\right.$ to $\left.-30^{\circ}\right)$ \\
Internal tibial torsion (post-operation) & $2^{\circ}\left(-4^{\circ}\right.$ to $\left.12^{\circ}\right)$
\end{tabular}

Figures 1-6 show the various stages from clinical photographs to the post-operation X-ray. Figure 7 is a line diagram of what the osteotomies should look like at the conclusion.

\section{Discussion}

The combined inverted-U metaphyseal and open-wedge epiphyseal osteotomy for Blount disease had a good outcome in most patients with satisfactory functional results. The procedure was not associated with any neurological or vascular complication. There was no skin necrosis or wound infection. However, there was dehiscence of the medial knee wound in a patient without associated infection. Reactionary haemorrhage occurred in four of the patients. This was not unexpected in patients operated under the effect of a tourniquet. 
Table 2. The complications following the combined antero-posterior inverted-U metaphyseal and open-wedge medial-epiphyseal osteotomy for advanced Blount disease.

\begin{tabular}{cc}
\hline Complications & Study group (Limb) \\
\hline Iatrogenic fractures & None \\
Reactionary haemorrhage & four \\
Compartment syndrome & None \\
Vascular injury & None \\
Peroneal palsy & None \\
Wound infection & None \\
Wound dehiscence & One \\
Skin necrosis & None \\
Osteomyelitis & None \\
Delayed union of osteotomy & None \\
Residual joint laxity & Two \\
Recurrence (At 24 months) & None \\
\hline
\end{tabular}

The minimal soft tissue dissection made possible by the use of both lateral and medial longitudinal incisions is likely to have contributed to the absence of compartment syndrome and vascular injury in this series of patients. The absence of common peroneal nerve palsy is likely to be due to the low level at which the fibula osteotomy was done. At the lower half of the fibula, the muscular branches of the peroneal nerve have been given off and this reduces the chance of peroneal nerve injury [13] [14].

The functional outcome of this study is similar to what was reported following the double elevating osteotomy using the Ilizarov device for slow correction of varus deformity [15] [16]. However, because of the absence of pins for external fixation there was no exposure to the risk of pin tract infection in our series. Hemiplateau elevation combined with epiphyseal distraction using an external fixator has also been used with similar satisfactory results [17].

The combined inverted-U and open-wedge medial plateau osteotomy allows for correction of limb length discrepancy in unilateral Blounts because an open wedge metaphyseal osteotomy is possible owing to the large surface area of the U-shaped osteotomy. It also enables the correction of varus and internal tibial torsion deformity as well as tibial procurvatum. The potential of this osteotomy for multiplanar correction is similar to what could be derived from the use of the Ilizarov's device or Taylor's spatial frame for correction of Blount disease [15]-[20].

In addition, this technique affords the surgeon the opportunity to repair the lateral collateral ligament which may contribute to recurrence if it remains lax. This view is without prejudice to the opinion that recurrence is usually linked to inadequate lateral epiphyseodesis [7] [16]. The additional reefing of the lateral collateral ligament may offer a transient lateral epiphyseal constraint.

The main drawback of this technique would be the scars from the three incisions. In order to improve the cosmetic outcome of the scars, we closed all wounds using subcuticular mattress skin closure. Furthermore, the risk of neurovascular injury arising from a near knee osteotomy was mitigated by the use of the twin longitudinal incisions which made adequate protection of the neurovascular structures around the knee reproducible.

However, the scarring that follow infected pin tracts are far more cosmetically unacceptable than a well healed incision just like a transiently misguided pin can cause more harm to vessels and nerves than the osteotome would in a properly done open procedure.

This technique will find use in patients with severe deformities who require multiplanar correction in any setting because, apart from the fact that it does not require more than the basic instrumentation for osteotomy, it is also devoid of the cumulative radiation risk to young patients and operating room personnel which may be enormous with the use of image intensifiers in high volume orthopaedic centers [21].

\section{References}

[1] Aird, J.J., Hogg, A. and Rollinson, P. (2009) Femoral Torsion in Patients with Blount’s Disease: A Previously Unre- 
cognised Component. Journal of Bone and Joint Surgery, 91, 1388-1393. http://dx.doi.org/10.1302/0301-620X.91B10.22554

[2] Thompson, G.H. (1988) Angular Deformities of the Lower Extremities. In: Chapman, M.W., Ed., Operative Orthopaedics, 2nd Edition, Lippincott, Philadelphia, 3139-3145.

[3] Canale, S.T. (1998) Osteochondrosis or Epiphysitis and Other Miscellaneous Affections. In: Canale, S.T., Ed., Campbell's Operative Orthopaedics, 9th Edition, Mosby, St. Loius, 891-901.

[4] Stricker, S.J., Edwards, P.M. and Tidwell, M.A. (1994) Langenskiold Classification of Tibia Vara: An Assessment of Interobserver Variability. Journal of Pediatric Orthopaedics (US), 14, 152-155. http://dx.doi.org/10.1097/01241398-199403000-00004

[5] Rab, G.T. (1988) Oblique Tibial Osteotomy for Blount’s Disease (Tibia Vara). Journal of Pediatric Orthopaedics, 8, 715-720. http://dx.doi.org/10.1097/01241398-198811000-00018

[6] Aoki, Y., Yasuda, K., Mikami, S., Ohmoto, H., Majima, T. and Minami, A. (2006) Inverted V-Shaped High Tibial Osteotomy Compared with Closing Wedge High Tibial Osteotomy for Osteoarthritis of the Knee. Ten Year Follow-Up Result. Journal of Bone and Joint Surgery, 88, 1336-1340. http://dx.doi.org/10.1302/0301-620X.88B10.17532

[7] van Huyssteen, A.L., Hastings, C.J., Olesak, M. and Hoffman, E.B. (2005) Double-Elevating Osteotomy for LatePresenting Infantile Blount's Disease: The Importance of Concomitant Lateral Epiphyseodesis. Journal of Bone and Joint Surgery, 87, 710-715. http://dx.doi.org/10.1302/0301-620X.87B5.15473

[8] Zayer, M. (1992) Hemicondylar Tibial Osteotomy in Blount’s Disease. A Report of 2 Cases. Acta Orthopaedica, 63, 350-352. http://dx.doi.org/10.3109/17453679209154801

[9] Gregosiewicz, A., Wosko, I., Kandzierski, G. and Drabik, Z. (1989) Double Elevating Osteotomy of Tibiae in the Treatment of Severe Cases of Blount’s Disease. Journal of Pediatric Orthopaedics, 9, 178-181. http://dx.doi.org/10.1097/01241398-198903000-00012

[10] Miller, S., Radomisli, T. and Ulin, R. (2000) Inverted Arcuate Osteotomy and External Fixation for Adolescent Tibia vara. Journal of Pediatric Orthopaedics, 20, 450-454. http://dx.doi.org/10.1097/01241398-200007000-00006

[11] Ogbemudia, A.O., Bafor, A., Edomwonyi, E. and Ogbemudia, P.E. (2008) Sterile Pneumatic Tourniquet Adapted from the Aneroid Sphygmomanometer: Technique and Results. Nigerian Journal of Orthopaedics and Trauma, 7, 45-47. http://dx.doi.org/10.4314/njotra.v7i2.29295

[12] Ogbemudia, A.O., Bafor, A. and Ogbemudia, P.E. (2010) Anterior Posterior Inverted-‘U’ Osteotomy for Tibia Vara: Technique and Early Results. Archives of Orthopaedic and Trauma Surgery, 131, 437-442. http://dx.doi.org/10.1007/s00402-010-1139-7

[13] Rupp, R.E., Podeszwa, D. and Ebraheim, N.A. (1994) Danger Zones Associated with Fibular Osteotomy. Journal of Orthopaedic Trauma, 8, 54-58. http://dx.doi.org/10.1097/00005131-199402000-00012

[14] Soejima, O., Ogata, K., Ishinishi, T., Fukahori, Y. and Miyauchi, R. (1994) Anatomic Considerations of the Peroneal Nerve for Division of the Fibula during High Tibial Osteotomy. Orthopedic Reviews, 23, 244-247.

[15] Hefny, H., Shalaby, H., El-Kawy, S., Thakeb, M. and Elmoatasem, E. (2006) A New Double Elevating Osteotomy in Management of Severe Neglected Infantile Tibia Vara Using the Ilizarov Technique. Journal of Pediatric Orthopaedics, 26, 233-237. http://dx.doi.org/10.1097/01.bpo.0000218530.59233.ab

[16] McCarthy, J.J., MacIntyre, N., Hooks, B. and Davidson, R.S. (2009) Double Osteotomy for the Treatment of Severe Blount Disease. Journal of Pediatric Orthopaedics, 29, 115-119. http://dx.doi.org/10.1097/BPO.0b013e3181982512

[17] Janoyer, M., Jabbari, H., Rouvillain, J.L., Sommier, J., Py, G., Catonné, Y. and Colombani, J.F. (2007) Infantile Bloun's Disease Treated by Hemiplateau Elevation and Epiphyseal Distraction Using a Specific External Fixator: Preliminary Report. Journal of Pediatric Orthopaedics B, 16, 273-280. http://dx.doi.org/10.1097/01.bpb.0000210591.35652.84

[18] Clarke, S., McCarthy, J. and Davidson, R. (2009) Treatment of Blount Disease: A Comparison between the Multiaxial Correction System and Other External Fixators. Journal of Pediatric Orthopaedics, 29, 103-109. http://dx.doi.org/10.1097/BPO.0b013e3181982a62

[19] Bar-On, E., Wiegl, D.M., Becker, T. and Katz, K. (2008) Treatment of Severe Early Onset Blount’s Disease by an Intra-Articular and a Metaphyseal Osteotomy Using the Taylor Spatial Frame. Journal of Children's Orthopaedics, 2, 457-461. http://dx.doi.org/10.1007/s11832-008-0140-y

[20] Pandya, N.K., Clarke, S.E., McCarthy, J.J., Horn, B.D. and Hosalkar, H.S. (2009) Correction of Blount’s Disease by a Multi-Axial External Fixation System. Journal of Children's Orthopaedics, 3, 291-299. http://dx.doi.org/10.1007/s11832-009-0172-y

[21] Levin, P.E., Schoen Jr., R.W. and Browner, B.D. (1987) Radiation Exposure to the Surgeon during Closed Interlocking Intramedullary Nailing. Journal of Bone and Joint Surgery, 69, 761-766. 